Doi: $10.24234 / \mathrm{se} .2020 .2 .2 .236$

\title{
CHILDREN WITH INTELLECTUAL DISABILITIES: CHALLENGES IN EDUCATION
}

\section{AUTHORS' DATA:}

Tereza Azatyan, $\mathrm{PhD}$ in Education, Associated professor

Chair of Special pedagogy and psychology, Khachatur Abovyan Armenian State Pedagogical University, Armenia

Head of the Chair, University lecturer

Contacts: azatyantereza41@aspu.am

Arevik Alaverdyan

2nd year graduate student, Special Education Program, Armenia

Contacts: arev_sun@mail.ru

\begin{abstract}
Educational policies aimed at school inclusion have led to increased enrollment of students with special education needs in mainstream schools. As a result, there is an increase in problems and challenges that children face while studying at school.

The article aims to highlight some of the difficulties and challenges that elementary school children with intellectual disorder face while studying in a mainstream school. In this study, we have conducted a literature review that examines the level of development of higher mental functions in children with intellectual development problems: attention, perception, thinking, memory, speech.
\end{abstract}

Keywords: intellectual disabilities, mental retardation, development, age, intelligence, language, perception, attention, thinking, memory. 


\section{INTRODUCTION}

The odd potential of intellectual disabilities in young children worldwide is a major concern. Realistic estimates suggest that approximately 780 million children may be affected between birth and five years' age (Olness, 2003). The number of young children likely to be affected by intellectual disability worldwide is eclipsed only by the diversity and complexity of the developmental patterns (Guralnick, 2005).

Reviewed evidence indicates that a substantial majority of children with intellectual delays exhibit special problems in studying as well as in forming peer relationships is school (Guralnick, 2006) which might be related to the development of higher mental functions. The highest and most complex level of human cognitive activity is thinking. Unlike other mental processes, thinking allows a person to operate with abstract concepts, make inferences and solve certain problems without interacting directly with an object, that is, thinking allows a person to go beyond the framework of sensory cognition. And such thinking processes like analysis, synthesis, comparison, abstraction, generalization, concretization help to acquire new knowledge (Schalock et al., 2010). Thinking is a generalized reflection of reality by a person, based on practical activity and sensual knowledge of the world, mediated by speech and acquired knowledge.

Intellectual disability, sometimes called cognitive disability, formerly referred to as mental retardation, is described as a disability characterized by significant deficits both in intellectual functioning and in adaptive behaviour as expressed in conceptual, social, and practical adaptive skills that occur before the age of 18 in which needs for supports become imperative (Schalock et al., 2010; Tassé, et. al, 2012). As Schalock et al. (2010) pointed out, intellectual disability results in impaired cognitive abilities and adaptive skills and the need for extraordinary supports for a person to participate in activities involved with typical human functioning. Intellectual disability is, therefore, not only an inherent trait of any individual, but also is characterized by a combination of deficits in both cognitive functioning and adaptive behavior in which systems of support become imperative.

The World Health Organization's International Classification of Functioning, Disability and Health (WHO, ICF 2007) defines disability within a bio-psychosocial model, which integrates both factors of the individual and his/her environment in defining disability. Within the WHO ICF framework, disability is viewed as impairment in body function or structure; limitation in activity; and restriction in participation (UNICEF \& University of Wisconsin, 2008). Therefore, the 
construct of disability has changed from focusing on a disorder within the person to a socioecological person-environment fit conception that focuses on understanding human functioning and disability based on the interactions between personal and environmental characteristics (Buntinx \& Schalock, 2010).

According to Schalock et al. (2010) and Tassé et al. (2012), the condition of intellectual disability is described and defined in terms of three major components: the deficits in intellectual functioning, adaptive behavior, as well as the needs of systems of support. However, there are no universal biomarkers associated with intellectual disability, hence, a determination of intellectual disability is made relying on a robust clinical evaluation of child functioning (Tassé et al, 2012).

\section{AIM AND METHOD}

Our research aims at pointing out the difficulties that elementary school children with the intellectual disorder face while studying in a mainstream school. The literature review method helps us to examine the peculiarities of these children, school difficulties in combination with the level of development of higher mental functions of children with intellectual development problems: attention, perception, thinking, memory, speech. An effective and well-conducted review as a research method creates a firm foundation for advancing knowledge and facilitating theory development (Webster \& Watson, 2002). Through integrating findings and perspectives from many empirical findings, a literature review can address research questions with a power that no single study has (Snyder, 2019).

For children with intellectual disabilities, thinking takes a special place. The development of this mental process plays an important role for educating the child, as well as for obtaining "life competencies", in order to prevent the child from "falling out" of society.

According to Vygotsky (1963), the thinking of children with learning disabilities develops according to the same laws and principles as the thinking of children without developmental disorders. But the disorder itself or the consequences of any disorder create conditions under which the child develops differently, his or her development follows a different path.

First of all, the thinking of children with learning disabilities is characterized by stereotyping, stiffness, and insufficient flexibility of thinking processes. That is why the implementation of new tasks among these children causes certain difficulties. 
When dividing an object into parts, children with intellectual disabilities often emit fewer parts of the subject than typically developing children. They easily isolate sharp and protruding parts of the object, but do not highlight those details that do not have sharp outlines. Children hardly distinguish parts of an object that are similar in color or other properties of their surface. Thus, for children in this category it is characterized by unsystematic analysis, the absence of sequentially complicated division of objects (Vygotsky, 1963).

When identifying the properties of objects, children most often indicate permanent signs common to all objects of this kind. Features and idiosyncrasies do not stand out. Also, due to speech impairment and a relatively small vocabulary, children cannot give a verbal description of the parts and properties of the subject, which interferes with the comprehension of the object being studied. Considerable difficulties for schoolchildren with intellectual impairment are comparing objects. The main disadvantage of this process is that children often correlate inappropriate signs of objects.

The book "Peculiarities of the Mental Development of Pupils of a Secondary School" by

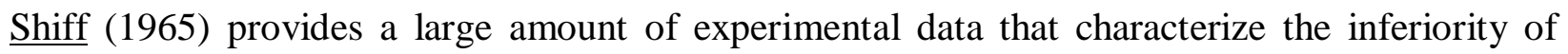
mental operations of children with impaired intelligence. So, for example, Zvereva and Lipkina (1953) concluded that when comparing objects, such children most often reveal differences in the objects they offer, but establishing similarities causes them certain difficulties, and sometimes children cannot establish similarities at all between items.

For children with intellectual disabilities, the development of perception is uneven, the acquired standards are often unstable, vague, there is no transfer of the learned mode of action from one situation to another. The relationships between the perception of a property, the ability to act with this property in mind, and the ability to make simple generalizations are quite complex. Children who successfully distinguish properties during classes cannot pick up paired items at the request of the teacher. They do not select them at all in everyday life, in independent activity, when you need to find a certain object in the room.

In the learning process, children learn the rules and general concepts with difficulty. Often, children with mental retardation memorize the rules by heart, but at the same time they do not understand the meaning or meaning of the learned rules. Therefore, the study of subjects requiring a clear understanding of the rules, such as the rules of grammar or arithmetic, presents the greatest difficulty for children with mental retardation. 
Pinsky (1999) revealed that children with intellectual disabilities have an impairment of the structure and motivation of activity. So, he notes an impairment of the relationship between the goal and the action, as a result of which the process of performing actions becomes formal, not designed to obtain really significant results.

Often, children with intellectual disabilities replace or simplify the goal, guided by their task. As a rule, schoolchildren with impaired intelligence perform the task without preliminary orientation in it, without proper analysis of the data and requirements contained in it.

Perova (2001), Pinsky (1999), and Shiff (1965) noted the ease of the approach of schoolchildren with intellectual disabilities to the task. Having accepted the task and having shown great activity and a desire to carry it out, students at the same time show a carefree attitude towards the mode of action leading to the desired goal. In some cases, they, having all the necessary knowledge and skills to solve the problem, are not able to solve since this knowledge and skills are not updated at the right time. Some of the students are not able to plan their activities.

According to Zvereva and Lipkina (1953), the most accessible form of thinking for elementary school children with intellectual disabilities is visual thinking. However, the children experience some difficulties when completing tasks. So, it's difficult for them to fold a simple cut picture or to correctly fill in the Segen board. Students have insufficiently developed practical actions. This is primarily due to the inferiority of sensory cognition and impaired motor sphere. At primary school age, child's actions with objects are often impulsive in nature, they are not associated with a mental task and have no cognitive value.

Vygotsky (1978) revealed that great difficulties for students with learning disabilities cause tasks involving the use of visual-figurative thinking. But tasks that require from children verballogical thinking are particularly difficult. So, for example, when considering a color plot picture, a child cannot always establish the cause-effect relationships reflected on it. Most often, children see and perceive individual parts of the picture, but do not understand the plot as a whole. It is difficult for them to understand texts containing temporary, causal or other relationships. Children reproduce the material in a simplified manner, omitting many, sometimes the most significant parts of it. They can change the sequence of semantic links of the text and not establish the necessary relationships between them.

Apart from learning difficulties, children with mental retardation may face many behavior disorders as well. Behaviour disorders are particularly important for children with mental 
retardation, since in addition to the subjective distress they cause the individual; they restrict opportunities to engage in many normal activities. McDougle and others (1997) found that children with mental disorders who had behaviour problems have reduced freedom of movement, social and self-help skills, have fewer leisure activities at home and fewer friends at school than those without such problems.

Mentally retarded children show behaviours that are considered as problematic because of the harm or inconvenience they cause others, or to the child himself. The presence of behaviour problems in mentally retarded children puts great strain on teachers. Besides, they may interfere with learning in the school/classroom settings (Venkatesan, 2004). The author emphasized that when a child with mental retardation calls out things, shouts or stamps its feet, people attribute these behaviour problems to his primary condition of mental retardation. This, is however, not true. Behaviour problems may be viewed as learned patterns of behaviour or as a function of the contingencies or rewards received by the children in their respective environment (Venkatesan, 2004).

Holden and Gitlesen (2006) reviewed the various studies which indicated that $10 \%-15 \%$ of people with mental retardation show challenging behaviour, like attacking others (aggression), self-injurious behaviour, destruction, disruptive or socially unacceptable acts. He indicated that the challenging behavior is more common among elementary school children, among males, and increases with lack of communication skills and severity of mental retardation.

Bogdanova (2005) investigated the role of needful-motivational, emotional-volitional and communicative spheres in the regulation of the behavior of students with mental retardation in the learning process. It was found that one of the most problematic abilities of students with mental retardation was motivational regulation of behavior.

Bogdanova (2005) notes that behavioral disorders in students with intellectual disabilities may be due to teacher activity mistakes. In this regard, the so-called situational behavioral disorders that were identified as a response to the lack of a correct approach on the part of the teacher were identified. Such violations were attributed to: situationally-demonstrative, situationally-aggressive, situationally-insecure, situationally hyperactive behavior.

The development of ordinary and full-fledged, as far as possible, thinking in children with mental retardation is difficult, but an often solvable task. Achievement of the solution to this 
problem is possible through specially developed special pedagogy teaching methods and techniques used in the early stages of child development.

\section{CONCLUSION}

The literature review shows that elementary school children with mental disabilities face many obstacles and difficulties while at school. From the outcome of our investigation it is possible to conclude that the main challenges and difficulties are the following:

- stiffness and insufficient flexibility of thinking processes;

- unsystematic analysis, the absence of sequentially complicated division of objects;

- speech impairment and a relatively small vocabulary prevent children from giving a verbal description of the parts and properties of the subject, which interferes with the comprehension of the object being studied;

- difficulties in establishing similarities between items;

- generalization of subjects;

- memorizing the rules by heart without understanding the meaning of the learned rules;

- lack of motivation;

- task completion without proper analysis of the data and requirements contained in it;

- activity planning;

- seeing and perceiving individual parts of the picture without understanding it as a whole;

- challenging behavior.

Within this scope, it is essential to be able to address the needs of children and their families as soon as it is possible. It means that early intervention here is highly required. It is also important to focus on issues that support the adaptations that are and will be necessary to strengthen those families, as well as enable and facilitate child development. The education of children with mental disabilities took on a greater impetus from the second decade of the last century and several methods have been developed since then. Newer and more innovative methods are constantly evolving, which augurs well for the future. It is hoped that new elaborated and developed methods will soon solve at least some of the problems and difficulties that children with mental disabilities face while at school. 


\section{REFERENCE LIST}

1. Bogdanova, M., V. (2005). Osobennosti psikhologicheskikh zashit pri psikhosomaticheskikh rasstrojstvakh (na primere chasto i dlitelno boleyushikh), Avtoreferet, Tomskiy gosudarstvennij universitet, Tyumen.

2. Buntinx, W., H., E., \& Schalock, R., L. (2010). Models of Disability, Quality of Life, and Individualized Suppors: Implications for Professional Practice in Intellectual Disability. Journal of Policy and Practice in Intellectual Disabilities, 7 (4).

3. Guralnick, M., J. (2006). Peer Relationships and the Mental Health of Young Children with Intellectual Delays, Journal of policy and practice in intellectual disabilities, Vol. 3(1), p.49-56.

4. Guralnick, M., J. (2005). Early Intervention for Children with Intellectual Disabilities: Current Knowledge and Future Prospects, Journal of Applied Research in Intellectual Disabilities2005,18, 313-324.

5. Holden, B., \& Gitlesen, J., P. (2006). A total population study of challenging behavior in the county of Hedmark, Norway: Prevalence, and risk markers. Research in Developmental Disabilities, 27: 456-465.

6. McDougle, C., J., Holmes, J., P., Bronson, M., R., Anderson, G., M., Volkmar, F., R., Price, L., H., \& Cohen, D., J. (1997). Risperidone Treatment of Children and Adolescents With Pervasive Developmental Disorders: A Prospective, Open-Label Study, Journal of the American Academy of Child \& Adolescent Psychiatry, Vol. 36 (5), pages 685-693.

7. Olness K. (2003). Effects on brain development leading to cognitive impairment: a worldwide epidemic, Journal of Developmental \& Behavioral Pediatrics 24, 120-130.

8. Perova, M., N. (2001). Practical and mental activity of children with mental retardation. Prosveshenie Press.

9. Pinskiy. B., I. (1999). The formation the of motor skills of students in a secondary school. Paradox Press, Minsk.

10. Schalock, R., Borthwick-Duffy, S., Bradley, V., Buntinx, W., Coulter, D., Craig, E., et al. (2010). Intellectual disability: Definition, classification, and systems of support (11th ed.). Washington: American Association on Intellectual and Developmental Disabilities.

11. Shiff, Zh., I. (1965). Peculiarities of the Mental Development of Pupils of a Secondary School. Prosveshenie Press. 
12. Snyder, H. (2019). Literature review as a research methodology: An overview and guidelines, Journal of Business Research, Vol.104, Pages 333-339.

13. Tasse', M. J., Schalock, R. L., Balboni, G., Bersani, H. A. Jr., Borthwick-Duffy, S. A. S. Spreat, \& Zhang, D. (2012). The construct of adaptive behavior: Its conceptualization, measurement, and use in the field of intellectual disability. American Journal on Intellectual and Devep- mental Disabilities, 117, 291-303. http://dx.doi. org/10.1352/19447558-117.4.291.

14. UNICEF and the University of Wisconsin (2008). Monitoring Child Disaibilty in Developing Countries: Results from the Multiple Indicator. Cluster Surveys. New York: UNICEF.

15. Venkatesan, S. (2004). Children with developmental disabilities: A training guide for parents, teach,ers and caregivers, New Delhi, Sage publication

16. Vygotski, L., S. (1963). Learning and Mental Development at School. (Original 1935) In: Simon, B. \& Simon, J. (Ed.) Educational Psychology in the USSR. (pp. 21-34). London, Routledge \& Kegan Paul.

17. Vygotsky, L., S. (1978). The interaction between learning and development. In M. Cole, V. John-Steiner, S. Scribner, and E. Souberman (Eds.), Mind in society. Cambridge, MA: Harvard University Press.

18. Webster, J., \& Watson, R., T. (2002). Analyzing the past to prepare for the future: Writing a literature review, Management Information Systems Quarterly, 26, p. 3.

19. World Health Organization (2007). International classification of functioning, disability and health: children $\&$ youth version: ICF-CY.

20. Zvereva, M. V., \& Lipkina, A.I. (1953). Comparison of objects by mentally retarded schoolchildren. In: Special Features of the Perceptual Activity of Pupils at a Special School (Izd. APN, RSFSR, Moscow, 1953). 